U.S. DEPARTMENT OF COMMERCE

NATIONAL OCEANIC AND ATMOSPHERIC ADMINISTRATION

Environmental Research Laboratories

\title{
A Program for
}

Evaluating Atmospheric Dispersion

From a Nuclear Power Station

JERROLD F. SAGENDORF

Air Resources Laboratory IDAHO FALLS, IDAHO May 1974 


\title{
ENVIRONMENTAL RESEARCH LABORATORIES
}

\author{
AIR RESOURCES LABORATORIES
}

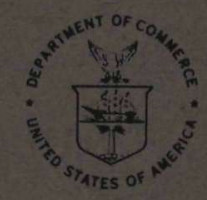

IMPORTANT NOTICE

Technical Memorends sre used to Insure prompt disseminstion of special studies which, though of Interest to the scientific community, may not be ready for formal publication. Since these papers may later be published in a modifled form to include more recent information or resescch results, abstracting, clting, or reproducIng this paper in the open literature is not encouraged. Contsct the suthor for additionsl information on the subject matter discussed in this Nomorandum.

NATIONAL OCEANIC AND ATMOSPHERIC ADMINISTRATION 


\section{DISCLAIMER}

This report was prepared as an account of work sponsored by an agency of the United States Government. Neither the United States Government nor any agency Thereof, nor any of their employees, makes any warranty, express or implied, or assumes any legal liability or responsibility for the accuracy, completeness, or usefulness of any information, apparatus, product, or process disclosed, or represents that its use would not infringe privately owned rights. Reference herein to any specific commercial product, process, or service by trade name, trademark, manufacturer, or otherwise does not necessarily constitute or imply its endorsement, recommendation, or favoring by the United States Government or any agency thereof. The views and opinions of authors expressed herein do not necessarily state or reflect those of the United States Government or any agency thereof. 


\section{DISCLAIMER}

Portions of this document may be illegible in electronic image products. Images are produced from the best available original document. 


\section{U.S. DEPARTMENT OF COMMERCE National Oceanic and Atmospheric Administration Environmental Research Laboratories}

NOAA Technical Memorandum ERL ARL-42

A PROGRAM FOR

EVALUATING ATMASPHERIC DISPERSION

FROM A NUCLEAR POWER STATION

Jerrold F. Sagendorf

Air Resources Iaboratory

Idaho Falls, Idaho

May 1974

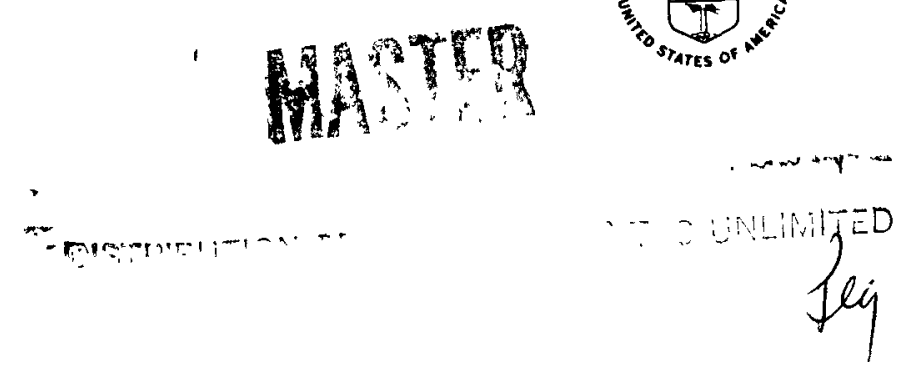




\section{DISCLAIMER}

The Environmental Research Laboratories do not approve, recommend, or endorse any proprietary product or proprietary material mentioned in this publication. No reference shall be made to the Environmental Research Laboratories or to this publication furnished by the Environmental Research Laboratories in any advertising or sales promotion which would indicate or imply that the Environmental Research Laboratories approve, recommend, or endorse any proprietary product or proprietary material mentioned herein, or which has as its purpose an intent to cause directly or indirectly the advertised product to be used or purchased because of this Environmental Research Laboratories publication. 


\section{CONTENTS}

\section{Page}

ABSTRACT

1

1. INTRODUCTION

1

2. INPUT DATA

1

3. MACHINE REQUIREMENTS

4. DESIGN BASIS ACCIDENT MODEL

5. ANNUAL AVERAGE MODEL

6. CALMS

7. EFFECTIVE STACK HEIGHT

8. OUTPUT

9. REFERENCE

APPENDIX A: INPUT DATA FOR PROGRAM

APPENDIX B: LIST OF SUBROUTINES 


\title{
A PROGRAM FOR EVALUATING ATMOSPHERIC \\ DISPERSION FROM A NUCLEAR POWER STATION
}

\author{
Jerrold F. Sagendorf
}

\begin{abstract}
A computer code (SEP for Site Evaluation Program) is described. The program uses a joint frequency distribution of winds and stability classes to evaluate the atmospheric dispersion potential near a nuclear power station. The code includes models for shortterm and long-term effluent releases. A description of the input parameters is included.
\end{abstract}

\section{INTRODUCTION}

This report describes a computer code developed for the Directorate of Licensing of the Atomic Energy Commission to evaluate atmospheric dispersion characteristics of potential sites for nuclear power stations. To do this, concentrations of effluents normalized by the source strength of the power plant are calculated. These atmospheric dilution factors are calculated for hourly and annual periods using data describing the power plant site and meteorology of the area.

\section{INPUT DATA}

A complete description of the input data necessary to run the program is given in appendix $A$. These data include a joint frequency distribution of wind speed and stability classes for each directional sector, the distances to the site boundary in each sector, the minimum distance to a site boundary, the distance to the nearest population center, and the cross section and height of the reactor building. If the site has a stack, the exit velocity of the effluent, the height and diameter of the stack, and the distances and elevations of significant terrain features for each sector must also be provided. 


\section{MACHINE REQUIREMENTS}

The program is written in FORTRAN IV and uses $250 \mathrm{~K}$ memory on an IBM 360/75 computer. Computing time varies depending on the options used and the size of the joint frequency distribution. A typical run using all the options and calculating both the surface and the stack effluent releases takes less than 1 min of computing time.

Plotting is done on an FR- 80 microfilm system. The plotting routines are separate from the calculating routines, so that the program can be run where an FR-80 is not available. In this case, core requirements would also be reduced.

\section{DESIGN BASIS ACCIDENT MODEL}

To evaluate the potential severity of an accident, atmospheric dilution factors are calculated for each hour in a year of "typical" weather conditions. One can then see the value of $x / Q$ (effluent concentration/source strength) that could be exceeded any given percent of the time. The calculations use the following equations:

$$
\begin{aligned}
& x / Q=\left[U\left(\pi \sigma_{y} \sigma_{z}+C A\right)\right]^{-1} \\
& x / Q=\left(3 U \pi \sigma_{y} \sigma_{z}\right)^{-1} \\
& x / Q=\exp \left[-\frac{1}{z}\left(h_{e} / \sigma_{z}\right)^{2}\right]\left(U \pi \sigma_{y} \sigma_{z}\right)^{-1}
\end{aligned}
$$

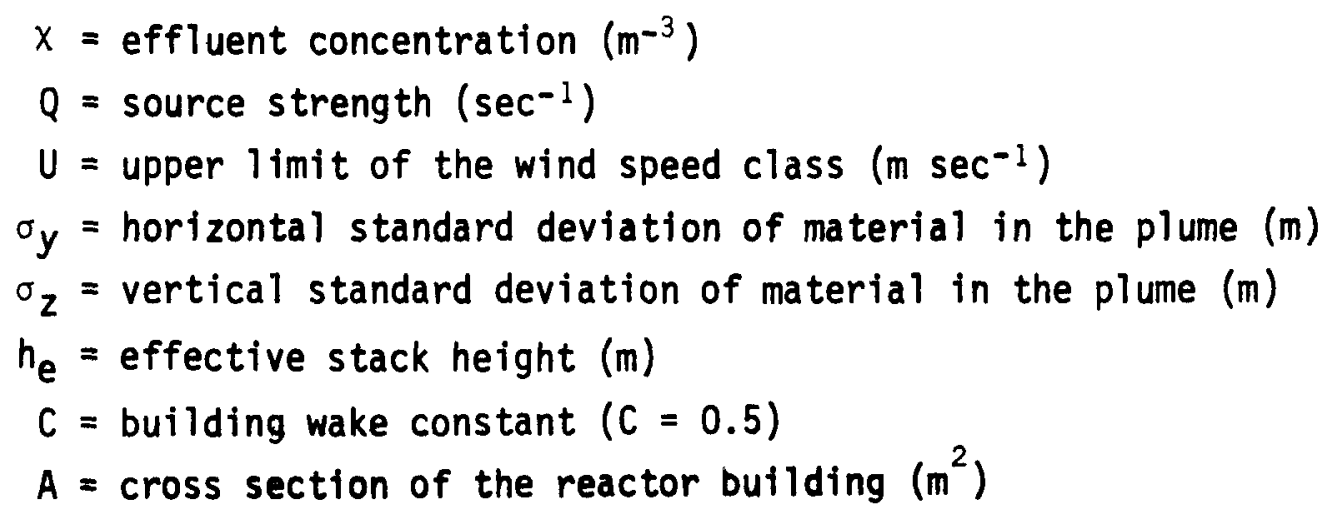


For a ground-level release, the results of (1a) and (1b) are compared and the larger value is used. Equation (1b) represents the limit allowed for building wake dilution. Values of $X / Q$ are calculated for all combinations of wind speed and stability classes using distances obtained in three different ways: (1) the distance to the nearest site boundary, (2) the distance to the nearest population center, and (3) the actual distance to the site boundary in each sector. In each case, the values of $X / Q$ are ordered from greatest to least, and the cumulative frequency is obtained from the joint frequency distribution. Finally a curve is fit to the $X / Q$ versus cumulative frequency data points, and the data points and curves are plotted on log-normal plots.

If a stack release is considered, (2) is used and the same procedures followed as for a ground release. In this case, however, the maximum value of $X / Q$ may occur at some distance beyond the considered distance. Because of this, calculations are made for a number of distances, and the maximum value of $X / Q$ at or beyond the considered distance is the one used.

\section{ANNUAL AVERAGE MODEL}

In this model, a long-term continuous release is assumed in order to evaluate the impact of a power plant under normal operating conditions. The equations used are

$$
\begin{aligned}
& \left(\frac{x}{Q}\right)_{\text {ave }}=\frac{(2 / \pi)^{\frac{3}{2}}}{r \theta} \sum \frac{f \exp \left[-\frac{1}{2}\left(\frac{h_{e}}{\sigma_{z}}\right)^{2}\right]}{\bar{U}\left(\sigma_{z}^{2}+\operatorname{co}_{z}^{2} / \pi\right)^{\frac{1}{2}}} \\
& \frac{\chi}{\text { ave }}_{\text {ave }}=\frac{(2 / \pi)^{\frac{1}{2}}}{r \theta \sqrt{3}} \sum \frac{f \exp \left[-\frac{1}{2}\left(\frac{h_{e}}{\sigma_{z}}\right)^{2}\right]}{\bar{U} \sigma_{z}}
\end{aligned}
$$

$\left(\frac{x}{Q}\right)_{\text {ave }}=\begin{aligned} & \text { annual average effluent concentration normalized by source } \\ & \text { strength }\end{aligned}$

$\bar{U}=$ average wind speed in the given wind speed class $\left(m \sec ^{-1}\right)$

$\sigma_{z}=$ vertical standard deviation of material in the plume $(m)$

$f=$ joint probability of stability, wind speed, and wind direction 


$$
\begin{aligned}
C & =\text { building wake constant }(C=0.5) \\
D_{Z} & =\text { height of the building }(m) \\
r & =\text { distance at which calculation is being made }(m) \\
\theta & =\text { sector width in radians. }
\end{aligned}
$$

Equation (3b) reflects the maximum allowable building wake dilution. The results of (3a) and (3b) are compared, and the larger value is used. Values of $(X / Q)$ ave are calculated for the site boundary and a number of distances out to $80 \mathrm{~km}$ for each sector. Each sector is divided into segments, and an average value of $X / Q$ is determined for the segments as follows:

$$
\begin{aligned}
& (x / Q)_{\text {seg }}=\frac{R_{1}(x / Q)_{R_{1}}+r_{1}(x / Q)_{r}+\cdots+r_{n}(x / Q) r_{n}+R_{2}(x / Q) R_{2}}{R_{1}+r_{2}+\cdots r_{n}+R_{2}} \\
& (x / Q)_{\text {seg }}=\text { average value of }(x / 10)_{\text {ave }} \text { for the segment } \\
& (x / Q)_{r}=(x / Q)_{\text {ave calculated at distance } r} \\
& R_{1}, R_{2}=\text { segment boundaries } \\
& r_{1} \cdots r_{2}=\text { selected radii between } R_{1} \text { and } R_{2} .
\end{aligned}
$$

The program has the option to assume mixing occurs between adjacent sectors. This option smoothes the values of $(x / Q)_{\text {seg }}$ as follows:

$$
\begin{aligned}
& \overline{(x / Q)_{K}}=\frac{1}{4}\left[(x / Q)_{K-1}+2(x / Q)_{K}+(x / Q)_{K+1}\right] \\
& \overline{(x / Q)_{K}}=\text { the smoothed value of }(x / Q)_{\text {seg }} \text { in the } K^{\text {th }} \text { sector } \\
& (x / Q)_{K}=(x / Q)_{\text {seg }} \text { in the } K^{\text {th }} \text { sector. }
\end{aligned}
$$

A second option that is also available averages all values of $(x / Q)_{\text {seg }}$ at each radii.

Note that the program can calculate values for a ground, an elevated, or a mixed release. For a mixed release, the origin is assumed to be at the reactor building; values obtained from an elevated release are interpolated into the appropriate radif surrounding the reactor. 


\section{CALMS}

Note that in (1a), (1b), (2), (3a), and (3b) wind speed appears as a factor in the denominator. This causes obvious difficulties in making calculations for calm periods.

The procedure used in the model is to assign a "direction" to each calm period according to the directional distribution for the lowest wind speed class. This is done separately for the calms in each stability category. In the rare instance that a stability category has calms but no occurrence of a lowest wind speed class, the calms are distributed evenly among all sectors. The calms are then added to the lowest wind speed class in the proper sector and stability category. The program also has the option of making the calms a separate wind speed class by assigning them some wind speed value and distributing them to the sectors in the same manner as above.

\section{EFFECTIVE STACK HEIGHT}

For elevated releases for both the accident and annual average models, effective stack height is determined from

$$
h_{e}=h_{s}+h_{p r}-h_{t}
$$

$h_{\mathrm{e}}=$ effective stack height $(m)$

$h_{s}=$ physical stack height $(m)$

$h_{p r}=$ plume rise (m)

$h_{t}=$ terrain height $(m)$.

The program interpolates linearly between terrain data points to obtain the terrain height at any given location.

Plume rise is calculated using formulas from Briggs (1969). The program will calculate plume rise caused by either momentum or buoyancy, depending on the heat emission rate $\left(Q_{h}\right)$ that is put into the program as data. Nuclear power stations generaliy have cold plumes, so the heat 
emission rate is read in as zero, and the plume rise is calculated from the momentum equations. For neutral or unstable conditions, we have

$$
h_{p r}=1.44\left(\frac{W_{0}}{U}\right)^{2 / 3}\left(\frac{X}{D}\right)^{1 / 3} D
$$

$$
\begin{aligned}
& h_{p r}=\text { plume rise }(m) \\
& W_{0}=\text { exit velocity }\left(m \sec ^{-1}\right) \\
& X \quad=\text { distance }(m) \\
& U=\text { wind speed }\left(m \mathrm{sec}^{-1}\right) \\
& D \quad=\text { internal stack diameter }(m) .
\end{aligned}
$$

When the exit velocity is less than 1.5 times the wind speed, a correction (Briggs, 1973; private communication) for downwash is subtracted from (7)

$$
C=3\left(1.5-\frac{W_{0}}{U}\right) D
$$

where $C$ is the value to be subtracted, and the other terms are defined as in (7). The result from (7), corrected by (8) if necessary, is compared with

$$
h_{p r}=3\left(\frac{W_{0}}{U}\right) D
$$

and the more conservative value is used.

For stable conditions, the results from (7) or (9) are compared with the results from the following two equations

$$
\begin{aligned}
& h_{p r}=4\left(\frac{F_{m}}{S}\right)^{1 / 4} \\
& h_{p r}=1.5\left(\frac{F_{m}}{U}\right)^{1 / 3} \mathrm{~s}^{-1 / 6},
\end{aligned}
$$

and the smallest value of $h_{p r}$ is used. In (10) and (11), $F_{m}$ is the 
momentum flux parameter and $S$ is a stability parameter. They are defined as

$$
\begin{gathered}
F_{m}=W_{0}^{2}\left(\frac{D}{2}\right)^{2} \\
S=\frac{g}{T} \frac{\partial \theta}{\partial z}
\end{gathered}
$$

$g=$ acceleration of gravity $(\mathrm{m} \mathrm{sec}-2)$

$T=$ ambient air temperature (deg $K$ )

$\partial \theta / \partial z=$ vertical potential temperature gradient $\left(\operatorname{deg} K^{-1}\right)$.

For the purposes of the program, $S$ was defined as $8.7 \times 10^{-4}$ for $E$ stability, $1.75 \times 10^{-3}$ for $F$ stability, and $2.45 \times 10^{-3}$ for $G$ stability.

If plume rise is to be calculated for a buoyant plume, the value of $Q_{h}$ (in cal sec-1 ) is read in as data. Plume rise to distances less than some distance $X^{*}$ is given by

$$
\begin{gathered}
h_{p r}=1.6 F^{1 / 3} U^{-1} x^{2 / 3} \\
F=4.3 \times 10^{-3}\left[\frac{\mathrm{ft} / \mathrm{sec}^{3}}{\mathrm{ca} / / \mathrm{sec}}\right] Q_{h} .
\end{gathered}
$$

For neutral and unstable conditions,

$$
\begin{aligned}
& x^{\star}=0.5 F^{2 / 5} h_{s}^{3 / 5}\left(h_{s}<1000 \mathrm{ft}\right) \\
& x^{\star}=33 F^{2 / 5}\left(h_{s}>1000 \mathrm{ft}\right)
\end{aligned}
$$

where $h_{s}$ is the stack height. At distances beyond $x^{*}$, plume rise under unstable and neutral conditions is calculated by

$$
h_{p r}=\frac{\left.1.6 F^{1 / 3} X^{\star^{2}} \frac{2 / 3}{5}+\frac{16}{25}\left(\begin{array}{l}
X \\
X^{\star}
\end{array}\right)+\frac{11}{5}\left(\begin{array}{l}
X \\
X^{\star}
\end{array}\right)^{2}\right]}{U\left(1+\frac{4 X}{5 X^{\star}}\right)^{2}} .
$$


At $X=5 X^{\star}$, the plume is assumed to reach its maximum height. In stable conditions, (14) holds to a distance $X=24 U S^{-\frac{1}{2}}$ after which the plume rise is given by

$$
h_{p r}=2.9(F / U S)^{1 / 3}
$$

where $S$ is given by (13) and the same values are used as for momentum. One other option available is simply to ignore plume rise.

\section{OUTPUT}

The output includes a printout of the maximum wind speed in each class and the frequency of occurrence of the wind speed class. Also printed out are the values of wind speed occurring at any desired increment of frequency, as determined by fitting a curve to the wind speed and cumulative frequency data point. A plot of the data points and the curve is also optionally available.

Similar tables and plots are included for the accident $x / Q$ calculations, and for the stack releases the plots and tables of the exponential term are included as well. For the annual average model, tables of annual average $X / Q$ versus distance and average values of $X / Q$ for each segment are printed out. If the site has a stack, the average effective stack height for each segment is printed out. Also included are the values of $(x / Q)_{\text {ave }}$ at the site boundaries and the average wind speed in each sector. Plots of $(x / Q)$ ave versus distance for each sector and contour maps of $(x / Q)_{\text {ave }}$ for an $80 \mathrm{~km}$ radius around the site are optionally available.

\section{REFERENCE}

Briggs, G. A. (1969): Plume Rise, USAEC Report TID-15075. Available from Clearinghouse for Federal Scientific and Technical Information National Bureau of Standards, U. S. Dept. of Commerce, Springfield, Virginia 22151. 
Appendix A: Input Data for Program

\begin{tabular}{|c|c|c|c|}
\hline $\begin{array}{l}\text { Card } \\
\text { Type }\end{array}$ & Columns & $\begin{array}{c}\text { Variable } \\
\text { Name }\end{array}$ & Format \\
\hline 1 & $1-14$ & KDPT & 1411 \\
\hline 1 & 1 & KDPT (1) & \\
\hline 1 & 2 & KDPT (2) & II \\
\hline 1 & 3 & KDPT (3) & II \\
\hline 1 & 4 & KOPT (4) & I1 \\
\hline 1 & 5 & KDPT (5) & II \\
\hline I & 6 & KDРТ (6) & I1 \\
\hline 1 & 7 & KDPT (7) & II \\
\hline 1 & 8 & КОРТ (8) & I1 \\
\hline 1 & 9 & КОРТ (9) & I1 \\
\hline 1 & 10 & KDPT $(10)$ & II \\
\hline 1 & 12 & KDРТ (ZZ) & II \\
\hline
\end{tabular}

$\omega$

\begin{tabular}{|c|c|c|c|}
\hline 1.2 & KDPT (12) & II & Adjust wind speed classes \\
\hline 13 & KDPT (13) & II & Include calms as a separate wind speed class \\
\hline 14 & KDPT (14) & I] & $\begin{array}{l}\text { Use } 30^{\circ} \text { sectors for north, south, east and west and } 20^{\circ} \text { sectors } \\
\text { for all other directions. }\end{array}$ \\
\hline $1-80$ & TITLA & $20 A 4$ & Title for the minimum boundary case \\
\hline $1-80$ & TITLB & $20 A 4$ & Title for the low population zone case \\
\hline $1-80$ & TITLC & 2044 & Title for the variable boundary case \\
\hline $1-80$ & TITLD & 2044 & General title for the site \\
\hline $1-80$ & TITLE & $20 A 4$ & Title for the mixed release case. Include only if $\mathrm{K \emptyset PT}(4)=1$. \\
\hline $1-5$ & NVEL & 15 & The number of velocity categories \\
\hline $6-10$ & NSTA & I5 & The number of stability categories \\
\hline $11-15$ & NDIR & 15 & The number of directional sectors (16 or 18). \\
\hline $16-20$ & NDIS & 15 & The number of distances for which terrain heights are given \\
\hline $21-25$ & NHRS & 15 & $\begin{array}{l}\text { The number of hours from which the joint frequency distribution } \\
\text { was obtained. If the joint frequency distribution is given in } \\
\text { percent set NHRS }=1 \text {. If NHRS is read in as a negative number, } \\
\text { it will be set to } 1000000 \text {. }\end{array}$ \\
\hline
\end{tabular}

KOPT is the option array. $1=$ do, $0=$ bypass

Design basic accident calculations

Annual average calculations

Ground-level release

Stack release

Printout input data

Plot results on microfilm

Printout individual $\times / Q$ calculations

Calculate plume rise

Use running mean smoothing on annual average sectors.

Calculate sector averages as a function of distance.

Mixed release calculations. (Submit data for ground-level release ahead of that for a stack and assign an internal storage device ahead of that

Adjust wind speed classes

Include calms as a separate wind speed class

for all other directions.

Title for the minimum boundary case

Title for the mixed release case. Include only if $\operatorname{K\emptyset PT}(4)=1$.

The number of stability categories

he number of hours from which the joint frequency distribution percent set NHRS = 1. If NHRS is read in as a negative number it will be set to 1000000 . 
Appendix A: Input Data for Program - Continued

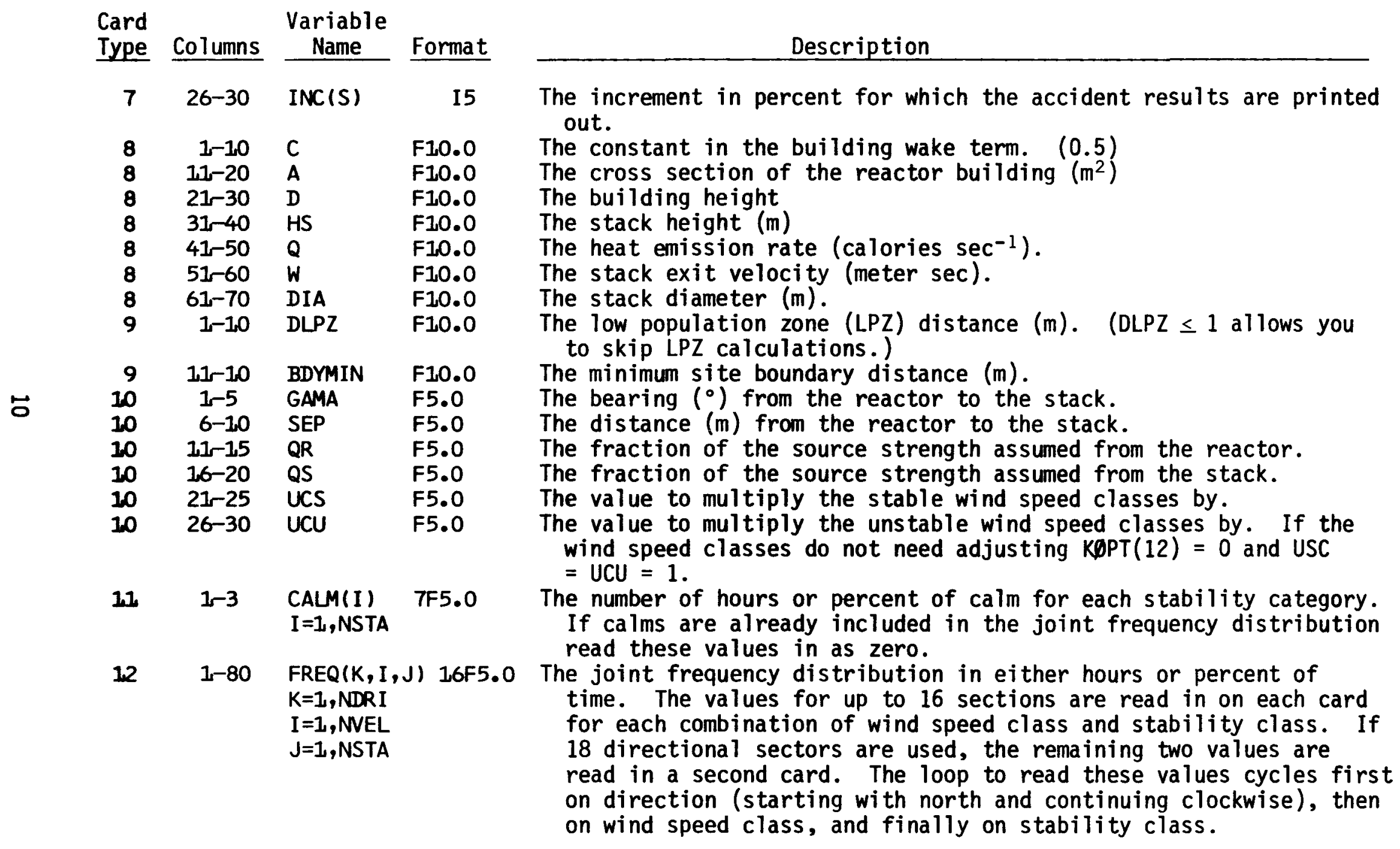




\section{Appendix A: Input Data for Program - Continued}

\begin{tabular}{|c|c|c|c|}
\hline $\begin{array}{l}\text { Card } \\
\text { Type }\end{array}$ & Columns & $\begin{array}{c}\text { Variable } \\
\text { Name } \\
\end{array}$ & Format \\
\hline 13 & $1-80$ & $\begin{array}{l}B D Y(K) \\
K=1, N D I R\end{array}$ & $8 F 10.0$ \\
\hline 14 & $1-80$ & $\begin{array}{l}\operatorname{DIST}(K, I) \\
K=1, N D I R \\
I=1, N D I S\end{array}$ & $8 F 10.0$ \\
\hline 105 & $1-80$ & $\begin{array}{l}H T(K, I) \\
K=1, N D I R \\
I=I, N D I S\end{array}$ & $26 \mathrm{~F} 5.0$ \\
\hline 16 & $1-35$ & $\begin{array}{l}\mathrm{CDR}(\mathrm{J}) \\
\mathrm{J}=1, N S T A\end{array}$ & $7 F 5.0$ \\
\hline 17 & $1-5$ & UCAR & F5.0 \\
\hline 17 & $6-75$ & $\begin{array}{l}\operatorname{UMAX}(I) \\
I=\mathrm{N}, \mathrm{NVEL}\end{array}$ & $14 \mathrm{F5}$ \\
\hline
\end{tabular}

Description

The distance ( $m$ ) to the site boundary in each directional sector. The values are read in eight to a card, beginning with the boundary to the south and proceeding clockwise until all sector boundaries are read in.

The distances ( $m$ ) at which the terrain heights are given. These values are read in eight to a card as for BDY above, except that NDIS distances are allowed. These cards are not read in for ground releases (i.e., if $\operatorname{K\emptyset PT}(4)=0$ ).

The terrain heights $(\mathrm{m})$ corresponding to the distances in the DIST array above. These values are read in the same order as DIST, except there are 16 values to a card. They are also skipped if $\operatorname{KOPT}(4)=0$.

An array of correction factors that may be applied to the joint frequency distribution. A different factor is possible for each stability class. If no corrections are needed, read in COR(1) as a negative value.

A correction factor that may be applied to the wind speed classes. $U C \emptyset R<0$ No corrections will be made. UCØR > 100 The wind speed classes will be converted from miles/ hour to $\mathrm{m} / \mathrm{sec}$.

The maximum wind speed in each wind speed class. The values may be in either miles/hour or $\mathrm{m} / \mathrm{sec}$. If given in miles/hour set UCØR to a value greater than 100 .

Note: Card type 6 (TITLE) is read in only if $\mathrm{K} \emptyset \mathrm{PT}(4)=1$. If no mixed release calculations are made, it may be included as a blank card.

Card types 14 and 15 (DIST and HT) are skipped if $\mathrm{K \emptyset PT}(4)=0$. 


\section{Appendix B: List of Subroutines}

\begin{tabular}{|c|c|c|}
\hline ANNUAL & - & Annual average model \\
\hline CHIQ & - & Design basis accident model \\
\hline CONV & - & $\begin{array}{l}\text { Used in transforming data points to the log-probability } \\
\text { graphs }\end{array}$ \\
\hline DATPLT & - & Plots the log-probability plots \\
\hline CORECT & - & Used if the wind speeds must be adjusted \\
\hline GAUSS & - & $\begin{array}{l}\text { Integrates by Gaussian method to determine area under } \\
\text { a normal curve }\end{array}$ \\
\hline INVERS & - & Matrix inversion routine used in least-square curve fitting \\
\hline ISOLIN & - & Plots contour maps of annual average $x / Q$ \\
\hline LOGPLT & - & Plots $x / Q$ distance on a $\log -\log$ graph \\
\hline LSTSQR & - & Fits curves by least-squares method \\
\hline MAIN & - & Reads input data \\
\hline ORDER & - & Orders data from greatest to least \\
\hline OUTPUT & - & Handles output for design basis accident case \\
\hline POLYN & - & Computes $\sigma_{y}$ and $\sigma_{z}$ \\
\hline RISE & - & Calculates plume rise \\
\hline REVORD & - & Orders data from least to greatest \\
\hline SHIFT & - & $\begin{array}{l}\text { Interpolates annual average } \times / Q \text { values from the stack to } \\
\text { radii around the reactor }\end{array}$ \\
\hline SPCOUT & - & $\begin{array}{l}\text { Handles output for wind speed vs cumulative frequency for } \\
\text { cases where the wind speeds must be adjusted. }\end{array}$ \\
\hline
\end{tabular}

